\title{
Violência escolar o desafio da atualidade: implicações na prática profissional do professor
}

\author{
School violence the challenge nowadays: implication in the \\ professional practice of teachers
}

\author{
Daiane Beatriz Meinhart \\ Graduada em Ciências Biológicas - Licenciatura, UFFS/RS \\ dbmeinhart@gmail.com
}

Eliane Gonçalves dos Santos Doutora em Educação nas Ciências, pela UNIJUÍ Universidade Federal da Fronteira Sul santoselianegoncalves@gmail.com

Resumo: Presenciamos nos meios de comunicação, muitas reportagens sobre violência no ambiente escolar, tanto entre alunos, como entre alunos e professores. Esta pesquisa teve como objetivo reconhecer e descrever, em teses e dissertações, as implicações geradas pela violência contra professores nas escolas e sua interferência no processo de ensino e aprendizagem, bem como analisar os conceitos que identificam as causas dessa violência. A pesquisa é documental com foco na Educação nas Ciências. A análise do material ocorreu a partir da Análise de Conteúdo. Emergiram duas categorias, a saber: i) Causas da violência contra professores; ii) Consequências da violência escolar e suas implicações nos processos de ensino e aprendizagem. A violência contra professores nas escolas é preocupante, pois tem provocado muitos malefícios à vida do professor, bem como aos processos de ensino e aprendizagem.

Palavras-chave: Violência na escola. Saúde do professor. Causas e consequências da violência. Ensino e aprendizagem.

Abstract: Nowadays we experience, in the means of communication, lots of news about violence in school among students as well as among students and teachers. The objective of this research is to recognize and describe in thesis and dissertation the implication generated by the violence against teachers at school and their interfere in the process of teaching and learning, as well as, analyse the concepts that identify the causes of this violence. The research is documental with the focus in Science Education. The analysis of the material happened trough the Content Analysis. Two cathegories emerge: i) Causes of violence against teachers; ii) Consequences of school violence and it's implication in the process of teaching and learning. The violence against teachers at school is alarming because it cause a lot of damage to teacher's life, as well as, the process of teaching and learning.

Key-words: Violence at school. Teachers health. Causes and consequences of the violence. Teaching and learning. 


\section{Introdução}

A escola é um espaço onde se busca a construção de saberes e a socialização do indivíduo, a fim de que o mesmo desenvolva suas capacidades emocionais e intelectuais e esteja preparado para viver na sociedade contemporânea. Consiste em um espaço que predomina a amizade e o respeito, porém "o foco educacional torna-se distorcido, devido aos números alarmantes de casos que envolvem violência contra professores" (MATOS; VIANA; GURGEL, 2012, p.3).

Nos últimos anos, presenciamos nos meios de comunicação, muitas reportagens sobre violência no ambiente escolar, tanto entre alunos, como entre alunos e professores. A violência contra professores nas escolas é preocupante, pois sabemos que tal problema tem provocado muitos malefícios à vida do professor, bem como aos processos de ensino e aprendizagem.

Martins e Torres (2016, p.1) acrescentam que "as escolas não têm sido mais um ambiente de segurança e proteção, o que se tem visto é um aumento generalizado da violência, agressões físicas e verbais, tráfico e consumo de drogas tem sido parte do cotidiano de diversas instituições de ensino".

Em uma pesquisa de ordem global (TENENTE; FARJADO, 2017), o Brasil ocupa o primeiro lugar no ranking de violência contra professores. A pesquisa foi realizada em 2013, pela Organização para a Cooperação e Desenvolvimento Econômico (OCDE), com mais de 100 mil professores e diretores de escolas do segundo ciclo do ensino fundamental e do ensino médio. $\mathrm{Na}$ enquete $12,5 \%$ dos professores ouvidos no Brasil disseram ser vítimas de agressões verbais ou de intimidação de alunos pelo menos uma vez por semana. Os dados assustam, pois se trata do índice mais alto entre os 34 países pesquisados, cuja média fica em torno de 3,4\%.

A violência pode ser manifestada de inúmeras formas, que vão desde agressões verbais e psicológicas, até as formas mais graves, como a agressão física. Todo tipo de agressão pode influenciar, direta ou indiretamente, a motivação profissional dos docentes em sala de aula, “[...] afetando sua prática e desqualificando um dos objetivos da escola que é o ensino e aprendizagem dos alunos" (MATOS; VIANA; GURGEL, 2012, p.5).

Percebe-se que a atuação do professor em sala de aula é prejudicada, "o mesmo, que deveria preparar as aulas e preocupar-se com a aprendizagem dos seus alunos, fica sem saber como agir, como resolver os problemas e as situações de conflito que se apresentam no dia a dia escolar" (SODRÉ; MOURA; ALEXANDRE, 2012, p. 316). 
Por isso, quando os comportamentos dos alunos não correspondem com os propósitos educativos, muitas vezes surgem os atos de indisciplina em sala de aula, "essa indisciplina causa principalmente a impossibilidade do professor ministrar sua aula, e por outro lado, a dificuldade dos alunos em aprender por estar associada à desordem" (FONSECA, 2011, p.8).

Matos, Viana e Gurgel (2012) apontam que a família, a escola e o Estado são todos encarregados de melhorar o relacionamento entre professores e alunos, evitando dessa forma atitudes violentas de ambos os lados.

Os professores devem ser conscientizados e preparados para ensinar de acordo com a sociedade atual e não permanecer apenas com suas práticas tradicionais descontextualizadas com a realidade dos alunos; o Estado deve criar leis que ampare não apenas aos jovens, mas aos professores que são responsáveis pelo desenvolvimento dos alunos e do sistema escolar e a família deve acompanhar e participar da vida educacional dos filhos, dessa forma em conjunto com a escola poderá discutir e propor o desenvolvimento de medidas que priorizem o respeito aos professores e a convivência em harmonia no ambiente escolar e fora dele (MATOS; VIANA; GURGEL, 2012, p.10).

Lidar com o problema da violência escolar é um desafio da atualidade; contudo, a escola pode atuar em conjunto com a família e sociedade, em busca de alternativas para lidar com as situações de conflito, desenvolvendo com seus alunos um ambiente cooperativo e de respeito. $\mathrm{O}$ presente trabalho tem como objetivo reconhecer e descrever, em teses e dissertações, as implicações geradas pela violência contra professores nas escolas e sua interferência no processo de ensino e aprendizagem, bem como analisar os conceitos que identificam as causas dessa violência no ambiente escolar.

\section{Metodologia}

A pesquisa é qualitativa e de caráter documental (LÜDKE; ANDRÉ, 1986), com o intuito de analisar e sistematizar os conteúdos das obras que abordem violência escolar, preferencialmente no Ensino. Segundo Lüdke e André (1986, p.38), “a análise documental pode se constituir numa técnica valiosa de abordagem de dados qualitativos, seja complementando as informações obtidas por outras técnicas, seja desvelando aspectos novos de um tema ou problema”.

Os documentos (dissertações e teses) foram encontrados em bancos de dados de pesquisas científicas, disponibilizados na internet, tais como a Biblioteca Digital Brasileira de Teses e Dissertações (BDTD). A busca foi realizada por palavras-chaves ("violência escolar" e “violência contra professores"); pelos títulos dos trabalhos; pela leitura dos resumos e, em alguns 
casos, pela leitura do documento completo. Para o levantamento de dados, foram selecionados e analisados dez documentos publicados no período compreendido entre 2010 a 2017, os quais contemplavam os objetivos da pesquisa. No quadro abaixo estão listadas as teses e dissertações analisadas, organizadas por título, autoria das mesmas e ano de publicação. Para identificação, foram criados os seguintes códigos: dissertações (D1, D2, ..., Dn) e para teses (T1, T2..., Tn).

Quadro 1 - Teses e dissertações com a temática violência escolar contra os professores.

\begin{tabular}{|c|c|c|c|}
\hline Título & Autores & Ano & $\begin{array}{c}\text { Tipo de documento } \\
\text { - Tese (T) ou } \\
\text { Dissertação (D) }\end{array}$ \\
\hline $\begin{array}{l}\text { Educação, autoridade e } \\
\text { violência na escola: } \\
\text { entendendo relações no } \\
\text { diálogo com educadores. }\end{array}$ & $\begin{array}{l}\text { ASSIS, Jaqueline Tavares } \\
\text { de. }\end{array}$ & 2010 & $\mathrm{D} 1$ \\
\hline $\begin{array}{l}\text { Formação de professores e } \\
\text { violência nas escolas. }\end{array}$ & MARTINS, Eni de Fátima. & 2010 & T1 \\
\hline $\begin{array}{l}\text { Representações sociais de } \\
\text { violência contra professores } \\
\text { na escola. }\end{array}$ & SOARES, Michelle Beltrão. & 2013 & D2 \\
\hline $\begin{array}{l}\text { Sou professora e fui agredida: } \\
\text { a formação do professor para } \\
\text { enfrentar a violência da } \\
\text { escola. }\end{array}$ & CANTE,Vanderlei Bonoto. & 2014 & D3 \\
\hline $\begin{array}{l}\text { Moralidade e violência nas } \\
\text { escolas na visão dos } \\
\text { professores. }\end{array}$ & COSTA, Rodrigo César. & 2014 & D4 \\
\hline $\begin{array}{l}\text { A violência na escola e a sua } \\
\text { relação com fatores de saúde } \\
\text { geral e condições de trabalho } \\
\text { de professores. }\end{array}$ & NERI, Luana Valeriano. & 2014 & D5 \\
\hline $\begin{array}{l}\text { Violência escolar: formas de } \\
\text { manifestação e fatores } \\
\text { associados. }\end{array}$ & $\begin{array}{l}\text { GIORDANI, Jaqueline } \\
\text { Portella. }\end{array}$ & 2015 & D6 \\
\hline $\begin{array}{l}\text { Educar para a paz: } \\
\text { combatendo a violência na } \\
\text { escola. }\end{array}$ & $\begin{array}{l}\text { NASCIMENTO, Carla } \\
\text { Cristine Santos do. }\end{array}$ & 2015 & D7 \\
\hline $\begin{array}{l}\text { Autoridade enfraquecida, } \\
\text { violência escolar e trabalho } \\
\text { pedagógico: a percepção de } \\
\text { professores sobre a ruptura } \\
\text { dos vínculos de afeto e os } \\
\text { mal-estares no magistério. }\end{array}$ & $\begin{array}{l}\text { PEREIRA, Antonio Igo } \\
\text { Barreto. }\end{array}$ & 2016 & $\mathrm{~T} 2$ \\
\hline $\begin{array}{l}\text { Violência escolar: questões e } \\
\text { desafios para a gestão. }\end{array}$ & DIAS, Adriana Machado. & 2017 & D8 \\
\hline
\end{tabular}

Fonte: Autores, 2018.

De posse dos documentos, fez-se uma leitura mais detalhada e foram criadas categorias de análise, a partir da Análise de Conteúdo de Bardin (2011), constituída de três etapas fundamentais: a pré-análise, a exploração do material e o tratamento dos resultados e 
interpretação. A síntese dos dados resultantes da pesquisa foi organizada em categorias, a saber: i) Causas da violência contra professores; ii) Consequências da violência escolar e suas implicações nos processos de ensino e aprendizagem. Algumas vezes o texto analisado permeou-se entre uma e outra categoria de análise.

\section{Resultados e discussão}

A partir da análise dos dados empíricos emergiram duas categorias que contemplam a questão de investigação desta pesquisa: Quais são as implicações geradas pela violência contra o professor e qual sua interferência no processo de ensino e aprendizagem? Compreendemos que um dos principais desafios encontrados pelo professor está no comportamento do aluno. "Nos últimos anos, professores de escolas públicas e privadas tem sido alvo de inúmeras agressões físicas, verbais e psicológicas que direta ou indiretamente, influenciam em sua motivação profissional em sala de aula" (MATOS; VIANA; GURGEL, 2012, p.5). A falta de motivação, causada pela violência escolar, impede que os professores realizem seu trabalho de maneira satisfatória, prejudicando o desenvolvimento da aula e, consequentemente, a aprendizagem dos alunos.

Nesse sentido, também vale ressaltar que o fenômeno da violência escolar está relacionado a questões mais amplas e que envolvem diferentes esferas como a social, econômica, cultural, política etc. É importante ser ressaltado o atual contexto sócio-político e econômico brasileiro, modelo neoliberal, em que a defesa dos governantes de um estado mínimo soa como uma possibilidade de 'melhorar' a economia do país, mas, tal projeto somente agrava e acentua as desigualdades sociais e o acesso da grande maioria da população à saúde, à educação, entre outros direitos básicos.

É importante perceber que o Estado também é responsável pela violência, quando não cumpre com as responsabilidades que estão sob seu domínio, nesse sentido, colaboramos do entendimento de Oliveira e Martins (2006, p.92) quando citam que:

Como fenômeno histórico e social, uma das formas de sua manifestação é a violência estrutural. Ela é a violência do Estado contra o homem, caracterizada pela incapacidade do primeiro em realizar a justiça social para os adultos em geral, e às crianças e adolescentes que são destituídos, implícita ou explicitamente, do acesso à escola, à saúde e à assistência social. Um Estado que deixa parte significativa da população em situação de desemprego, carência, abandono e inúmeras outras iniqüidades é um Estado violentador, agente da opressão e facilitador das realizações da classe dominante. Estado este que abandona a família à sua própria sorte, num regime assistencialista e 
paternalista, violentando o indivíduo em suas tentativas de exercer sua cidadania.

Como já mencionado, o fenômeno da violência é algo complexo, pois este abarca questões que envolvem o desemprego acentuado, a banalização da violência pela mídia, o machismo, o aumento do uso de substâncias lícitas e ilícitas, as condições de vida da população numa sociedade globalizada em que o acesso aos bens básicos à vida são desiguais. Esses e outros fatores acabam refletindo no comportamento das pessoas, consequentemente essa violência que se origina na sociedade se reproduz nas escolas tanto da rede pública quanto na rede privada de ensino.

Daí decorre a necessidade de pensar e refletir sobre as causas da origem da violência escolar, como advogam Silva e Pereira (2008, p.915)

[...] violência e vulnerabilidade não estão isoladas das relações econômicas, políticas, culturais que configuram a estrutura de uma sociedade. Diversos estudos apontam que os condicionantes estruturais colocam ou aumentam a vulnerabilidade das pessoas ou grupos, e que a melhoria da situação sócioeconômica das famílias, e a garantia de políticas e serviços sociais, diferenciados, ajustadas e mais apropriadas para cada caso, são mediações para diminuir esta vulnerabilidade (Mckay; Lawson, 2002; Fundo das Nações Unidas para Infância [Unicef], 2005; Sánchez; Bertolozzi, 2007). Os determinantes sociais, econômicos e culturais somam-se aos fatores familiares e individuais para a determinação da vulnerabilidade à violência.

Nesse aspecto a violência escolar vai além da relação aluno -professor, como expressam Silva e Pereira (2008, p. 916) é decorrente da “ desigualdade social [...], mostra a incapacidade política e gerencial dos governos em incorporar sua população na cidadania, na garantia de direitos políticos, civis e sociais", tal situação que a população vivencia tem reflexos na escola, muitas vezes por meio de agressões físicas e verbais de crianças e jovens contra professores e demais sujeitos da comunidade escolar.

Pensando em alguns caminhos para minimizar ou modificar os índices de violência no espaço escolar, a formação profissional dos professores seria uma alternativa, pois de acordo com Cante (2014, p.107), “a formação inicial e continuada é fundamental na preparação dos professores para o enfrentamento dos desafios vividos na escola, inclusive, a violência escolar". Além disso, "é necessário que novas práticas educativas sejam pensadas, onde o aluno saiba que existe o direito, mas também o respeito e o dever" (SODRÉ; MOURA; ALEXANDRE, 2012, p. 322). Nesse sentido, é importante o papel da família, ao ensinar valores éticos e sociais a crianças e jovens para viver e conviver em sociedade. 
A violência escolar é um problema que afeta a todos, por isso é necessário criar espaços de diálogos e reflexão sobre o tema na escola, nas universidades e em outros espaços, para que assim se pensem e busquem estratégias para combater, minimizar e principalmente prevenir a violência no âmbito escolar. Destacamos que essa é uma das ações no âmbito educacional e familiar na busca pela diminuição da violência escolar, que o enfrentamento da questão deve vir do Estado a partir de políticas públicas e intervenções que visem o acesso da população à: moradia, segurança, emprego, saúde e educação. Apresentamos nos próximos tópicos as categorias que abordam as causas, as consequências da violência escolar.

\section{1) Causas da violência contra professores}

O cenário social tem como umas das principais características o alto índice de violência (MOTA; SANTOS, 2011). E essa violência também chega à escola. Situações como discussões familiares, desrespeito e xingamentos constantemente presenciados através da mídia, na comunidade e até mesmo em casa são naturalizadas no meio social, razão pela qual essas atitudes são refletidas também nas escolas (MOTA; SANTOS, 2011). Como indicam especialistas, a violência escolar também pode ser fruto de inúmeros fatores, entre eles: a condição financeira na qual se encontram as crianças e os jovens, o envolvimento dos alunos com drogas e álcool, a localização da escola e, especialmente, a desestrutura familiar.

De acordo com a autora D2 (2013, p.17) “a escola não consegue impedir que a violência se manifeste em seu interior, visto que ela interage em todos os sentidos com a sociedade e acaba por absorver também os fenômenos que se alastram em outras esferas sociais". Tal situação também é evidenciada nos trabalhos D2, D4 e D7, que sugerem uma relação direta entre a violência escolar e a desigualdade social dos alunos, ou seja, o contexto econômico também é responsável por atritos neste espaço. Segundo os autores dos textos D2, D4 e D7, uma sociedade desigual reproduz alunos revoltados e pobres de valores considerados essenciais para a convivência cidadã.

Os professores apontaram a violência contra eles mesmos como decorrência de uma desestrutura social e econômica, que gera desde a violência física até a violência simbólica. $\mathrm{O}$ aluno, proveniente de uma sociedade que o mantêm em constante violência simbólica, negando-lhe direitos básicos, reproduz na escola aquilo que recebe da sociedade. A contradição de uma sociedade desigual pode contribuir para manifestações de violência (D2, 2013, p.114).

Os textos D1, D2, D6 e D7 ressaltam que um dos fatores que tem sido associado à violência e que pode afetar as atitudes dos jovens é o envolvimento com drogas e álcool. O autor 
T2 destaca que os alunos em situação de vulnerabilidade e que moram em grandes centros urbanos são expostos, desde pequenos, a inúmeras adversidades, como:

Tráfico e consumo de drogas, bebedeiras, brigas, vandalismos, espancamentos, assaltos, furtos, abusos sexuais, homicídios, que ocorrem na rua, entre amigos ou mesmo dentro de casa. Muitos comportamentos dos alunos são reflexos dessas experiências de seu dia a dia, e que a frieza com que tratam determinadas situações resulta do fato de terem não somente incorporado, mas, sobretudo, naturalizado a hostilidade do lugar onde vivem (T2, 2016, p.184).

Outra causa que contribui para o cenário da violência escolar é o local onde a escola está inserida (SOARES, 2013). Segundo D2, D6 e T2, o contexto onde a escola está localizada, ou seja, o bairro, pode ter influência significativa no interior escolar. Partindo deste pressuposto, se a escola se encontra em um bairro violento, consequentemente ela enfrentará problemas de violência e de indisciplina dos alunos devido a este fator (D2, 2013).

Essa situação foi evidenciada na pesquisa feita pelo autor do trabalho T2, realizada em uma Escola Pública Estadual de Ensino Médio da cidade de Rio Branco (AC), na qual foram entrevistados professores e alunos acerca da violência escolar. Por meio do estudo, foi possível constatar que "a escola, pelo fato de estar situada em um bairro periférico, considerado lugar de grande incidência de crimes violentos, de tráfico e consumo de drogas, de vandalismo e de bebedeira, sofreria inevitavelmente seus reflexos" (T2, 2016, p. 213).

D1, D3, D4, D6, D7 e D8 destacam a educação familiar e a falta de limites como fatores fundamentais para os comportamentos violentos dentro das escolas, sobretudo com ênfase à negligência familiar como responsável pelas condutas violentas dos alunos e como os valores transmitidos pelos pais estão diretamente ligados às atitudes dos seus filhos na escola. De acordo com os trabalhos supracitados, os pais participam pouco da educação dos filhos, e muitas vezes consideram a escola responsável por grande parte do processo educativo, social e moral dos estudantes.

O autor D3 (2014, p.95) menciona que "os professores são agredidos por jovens que, geralmente, vivenciam a violência na própria família, são vítimas de agressões ou, então, não vivem em uma família estruturada para ensinar os primeiros conhecimentos que iriam auxiliá-los na formação de sua personalidade”. Para complementar o excerto supracitado, D4 (2014, p.18) afirma que "um ambiente familiar conflituoso, hostil e negligente contribui para a baixa autoestima dos jovens, culminando na prática de comportamentos agressivos e alimentando as condutas violentas". 
A partir da análise dos textos D1, D3, D4, D6, D7 e D8, percebe-se que os autores reconhecem a família como sendo determinante no comportamento dos filhos. Eles apontam que muitas famílias não estariam cumprindo sua função de forma adequada, sendo omissas aos problemas dos jovens. Também mencionam a falta de limites advinda da educação familiar como causadora da violência dos alunos nas escolas.

A esse respeito, aparentemente na contemporaneidade os pais têm tido cada vez mais dificuldades na educação de seus filhos. Descobrir o limite entre a liberdade e o autoritarismo na relação familiar parece ser muito mais difícil do que alguns anos atrás. Os pais "modernos" parecem não gostar de frustrar seus filhos (D2, 2013, p.100).

De acordo com D4 (2014, p.86), "a família é a base de toda constituição de boas condutas dos sujeitos, e a sua negligência seria a responsável pela estruturação de uma criança problema”. Isto significa que muitos pais transferem para a escola uma responsabilidade que é sua, atribuindo à escola todo papel de educar seus filhos, o que é um erro, pois a família é a base da educação, que ensina os limites que cada um deve ter e a viver em sociedade (MARTINS; TORRES, 2016).

A dinâmica familiar consiste em dar suporte aos valores, regras, afeto, empatia, entre outros fatores, e são essas características que possibilitam o desenvolvimento do indivíduo no aprendizado e nos bons comportamentos, e a ausência destes padrões pode ocasionar um desenvolvimento insatisfatório que, por sua vez, pode culminar em problemas no comportamento e na aprendizagem, como se observa em alguns alunos nas escolas (D4, 2014, p. 69).

Para Soares (2013) os meios de comunicação (celular, notebook, televisão, etc.), podem ser fontes para que a violência se propague entre os jovens. Os textos D1, D3, D4, D7 apontam a mídia como grande influência nos comportamentos dos jovens, pois apresenta frequentemente cenas de agressão física e moral, que são interpretadas de formas diferentes, o que influencia os comportamentos dessas crianças e adolescentes.

Pode-se afirmar que a discussão travada entre mídia e violência escolar é balizada pela crise de valores atuais, a mídia influencia o jovem a adotar comportamentos consumistas, violentos e até mesmo estimular a erotização juvenil, visto o conteúdo de alguns programas veiculados como apelo para o aumento da audiência (D2, 2013, p.141).

Segundo D7 (2014), em muitos casos as constantes manifestações de agressividade com a qual a criança convive (família, mídias) podem contribuir para a reprodução desses comportamentos e atitudes. 
A postura do professor também pode contribuir para que os estudantes tenham atitudes inadequadas. O comportamento autoritário e agressivo por parte dos agentes responsáveis por sua educação, professores que humilham os alunos e tratam com desprezo, não levando em consideração a autoestima dos envolvidos (OLIVEIRA; SOUZA, 2014). Se o professor abusa da sua autoridade docente, consequentemente ele terá um retorno não desejado de seus alunos. "Nessa perspectiva, se torna rara a aproximação do professor com a figura do aluno, a fim de que ambos compartilhem o saber" (D4, 2014, p.17).

Routti (2010, p. 354) afirma que "respeitar o outro também constitui um processo de aprendizagem, e a escola pode e deve ser um espaço privilegiado para tal fim”. Nesse sentido, “deve haver um equilíbrio das duas partes, o aluno respeitando o professor como autoridade em sala de aula, e o professor respeitando o aluno como humano em processo de aprendizagem, formação de valores e construção de novos conhecimentos" (CABRAL; CARVALHO; RAMOS, 2004, p.2).

É extremamente importante que o professor tenha uma relação próxima com seu aluno, dialogando e se interessando pelo que ele pensa. "Num modelo tradicional de ensino, o professor na sala de aula ensina e dá ordens e os alunos aprendem e obedecem" (CABRAL, CARVALHOS; RAMOS, 2004, p.2). Dessa maneira, fica difícil uma proximidade entre professor e aluno, acarretando atos indisciplinares por parte dos discentes. Por isso, é importante que docentes revejam e (re)avaliem suas posturas dentro da sala de aula, "pois se os estudantes são indisciplinados ou violentos pode ser que grande parte desta agressividade seja uma expressão de indignação deles por causa das atitudes dos agentes educacionais" (OLIVEIRA; SOUZA, 2014, p.10).

Dado ao exposto, percebe-se que a escola sozinha não tem o poder de reverter esse processo de violência das crianças e dos jovens em relação à figura do professor; ela precisa do apoio da família, ensinando a ter respeito e a se comportar educadamente com outras pessoas e do Estado na implantação de políticas públicas que visem os direitos econômicos e sociais dos sujeitos. Juntas, essas três esferas podem reverter essa situação e tornar a escola um ambiente de boa convivência. $\mathrm{Na}$ próxima categoria apresentamos as consequências da violência escolar.

\section{2) Consequências da violência escolar e suas implicaçoes nos processos de ensino e aprendizagem}

Muitas são as atribuições dadas ao professor e muitos são os desafios enfrentados em sala de aula, entre eles o controle de classe, dinamismo e domínio conceitual. Mota e Santos (2011) 
afirmam que não é fácil exercer uma profissão tão importante para a formação de pessoas e ao mesmo tempo tão pouco valorizada pela sociedade. Com base nas análises feitas anteriormente, verificou-se que "a violência contra o professor sofre os reflexos da classe social a que pertencem os alunos, das comunidades em que estão inseridos, da família da qual fazem parte e das mídias a que têm acesso" (SOARES, 2013, p.136).

Pela análise dos textos D1, D2, D4, D5, D7, T1 e T2, foi possível observar que as principais queixas dos professores em relação à violência são: violência verbal, violência física, violência psicológica, indisciplina e a desconstituição da sua autoridade.

Bem mais frequentes que a violência física são as agressões verbais e o assédio moral sofridos pelos professores. Embora de difícil mensuração, esses tipos de violência são reais e causam sérios efeitos ao quadro de mal-estar docente. A sensação de desamparo e de impotência são alguns dos seus reflexos e, se persistentes e não tratados, podem levar a consequências mais graves, afetando diretamente o trabalho do professor (T2, 2016, p.165).

O desrespeito dos alunos causa um sentimento de desânimo, que pode influir diretamente nas práticas docentes. Essa falta de expectativa do professor faz com ele questione e repense seu papel na escola. "Ser agredido em sala de aula, ou se sentir assediado pela instituição, faz com que os professores repensem o valor da sua profissão, acende o sentimento de desrespeito, de desvalorização profissional perante a sociedade” (D2, 2013, p.129).

Os estudos de D6 (2015) indicaram que sofrer agressões na escola é um fator de risco para a qualidade de vida do sujeito. Os relatos dos professores referem-se também à dificuldade para trabalhar após uma situação de conflito e sobre o quanto esses casos de violência afetam a rotina de trabalho. Sentimentos de desvalorização profissional e de solidão nas situações de conflito com alunos podem se refletir em afastamentos do trabalho e até o abandono ${ }^{1}$ da carreira docente.

Os textos D1, D2, D5, D7 e T2, abordam as dificuldades no trabalho pedagógico com alunos envolvidos com drogas, que acarretam comportamentos destrutivos e não positivos à saúde do sujeito. $\mathrm{Na}$ escola, esta situação ocasiona aos professores exaustão emocional, dado o contexto de risco em que se encontram.

Ao mesmo tempo em que classificam a indisciplina como "toda a ação que se opõe à regra", ela também é vista como algo que desarticula e impossibilita "a aprendizagem individual e coletiva, trazendo como prejuízo maior o esgotamento do mediador dessa aprendizagem: o professor". As expressões de indisciplina foram caracterizadas de diversas formas, como "na conversa

\footnotetext{
${ }^{1}$ Disponível em: <http://g1.globo.com/jornal-nacional/noticia/2015/02/aumenta-o-numero-de-professores-queabandonam-salas-de-aula.html>. Acesso em: 12 nov. 2018.
} 
paralela, brincadeiras inadequadas, falta de respeito entre os colegas e com o professor, agressão, etc", além de ações mais graves como "pichações, ameaças ostensivas e/ou veladas, acidez no vocabulário e até agressões físicas" (D1, 2010, p. 97).

Conforme D4 (2014, p.14), "grande parte dos educadores está à beira de surtos, pois as constantes bagunças suscitadas pelos estudantes não deixam esses profissionais exercerem suas metas, e a figura do professor já não é mais respeitada: virou motivo de chacota dentro das salas de aula". O professor, que outrora fora um profissional respeitado, hoje, já não possui a valorização merecida. Em meio às práticas de violência, os docentes se veem impossibilitados de ministrar suas aulas de maneira satisfatória, o que muitas vezes os desestimula a seguirem em frente na profissão (SOARES, 2013).

Os trabalhos D1, D2, D3 e T2 mencionam a síndrome de Burnout com uma das consequências da violência que os professores enfrentam na atualidade. Também chamada de Síndrome do Esgotamento Profissional, foi definida por Herbert J. Freudenberger, no início dos anos 1970. "É considerada uma modalidade de stress ocupacional, provocada por condições desgastantes no trabalho, que atinge profissionais no desempenho de funções assistenciais" (LEVY; NUNES SOBRINHO; SOUZA, 2009, p.459).

O sofrimento dos professores se relaciona, portanto, com a chamada "síndrome de Burnout". Os professores, acometidos por esta síndrome, vivem sob uma situação crônica de tensão emocional, de insatisfação com o que fazem, mas persistem (ao menos por determinado período) na docência em situação de desconforto (D2, 2013, p. 103).

D2 (2013, p.119) afirma que nesta síndrome “os professores são acometidos de uma alienação, uma forte sensação de impotência diante das situações adversas enfrentadas por eles, demonstram-se insatisfeitos, apáticos, infelizes e críticos". Tal cenário indica que o professor se sente desvalorizado mediante as situações de contestação da sua autoridade, de sua capacidade profissional, provocada pela violência sofrida no seu ambiente de trabalho (D1, D2, D3 e T2). Destaca-se, nesse sentido, que os educadores reconhecem sua responsabilidade na formação dos jovens, contudo eles se sentem sobrecarregados e sozinhos na tarefa de educar (D1, 2010).

Ainda há, em relação aos professores, uma sensação de impotência, de que ninguém os escuta, que sua autoridade de professor não é respeitada e muitos nem reconhecem em si essa autoridade. Esse silêncio revela, também, o medo de, ao exporem o problema, serem taxado de sem pulso para dominar a situação, de incompetentes, decadentes e de que é vergonhoso vivenciar uma situação de agressão (D3, 2014, p.100). 
De acordo com excerto acima, está cada dia mais difícil trabalhar na educação. Muitos professores que sofrem violência física, psicológica, moral, sofrem calados, pela dificuldade de lidar com essa situação, o que gera desgaste emocional, estresse, e, em certos casos, as depressões devido às agressões vivenciadas na escola.

Os professores, mesmo os mais qualificados, se queixam de que enfrentam, nos dias atuais, sérios problemas na escola, por conta do enfraquecimento de sua autoridade, como a violência dos alunos, cujas consequências têm sido o desgaste e a frustração profissional. Muitos acabam adoecendo ou mesmo desistindo da profissão por não conseguirem exercer seu trabalho (T2, 2016, p.17).

Os professores estão desgastados com a profissão, por serem "afrontados, desrespeitados e sentem-se agredidos pelas microviolências cotidianamente sofridas" (T2, 2016, p. 19). Neste sentido, o desrespeito dos alunos contribui em grande parte para isto, pois, sem o mínimo de autoridade, respeito e dignidade, os professores não podem exercer plenamente sua docência (ROUTTI, 2010).

Os profissionais da educação expressam que a autoridade dos tempos modernos não é a mesma do passado. Afirmam que, se forem muito legais, podem não ser levados a sério pelos alunos e se tornar motivo de brincadeiras de mau gosto; do mesmo modo, os que são extremamente rígidos, que exigem disciplina e respeito, também podem se tornar alvo da violência, já que os alunos podem se sentir ameaçados ou prejudicados, de alguma forma (T2, 2016). Em outras palavras, os professores considerados bonzinhos são ridicularizados pelos alunos, assim como os muito rígidos são alvos de ataques.

Para se obter respeito dos alunos, é necessário assumir uma postura diferente de autoritarismo (CABRAL; CARVALHOS; RAMOS, 2004). De acordo com D1 (2010, p.76), “a autoridade deve ser alcançada de modo legítimo e não imposto, de forma que os próprios alunos percebam essa autoridade". Nesse sentido, para conquistar esta autoridade, é necessário que os professores tenham clareza do seu papel, da sua competência técnica, do seu domínio e até do desejo de ensinar (D1, 2010).

A partir da análise destes trabalhos, percebe-se o quanto a violência escolar prejudica o trabalho do professor, pois à medida que são alvos de ameaças, agressões e desrespeitos, têm dificuldade em lidar com tal situação, uma vez que a maioria dos alunos (agressores) não aceita a imposição de normas ou orientações a serem cumpridas. São esses alguns fatores que desestimulam professores a seguirem em frente na profissão. 
Essas questões nos levam a refletir que um dos caminhos para o bom relacionamento entre professores e alunos é criar um vínculo afetivo com diálogo e respeito mútuo, em que deve haver um comprometimento de quem ensina com quem está ali para aprender.

\section{Considerações finais}

A violência na escola é um tema bastante complexo e que envolve a sociedade como um todo. Diante deste contexto, compreende-se que a violência e a indisciplina são realidades presentes na maioria das escolas, levando a situações de desequilíbrio no funcionamento escolar, o que resulta em prejuízos para o desenvolvimento do aluno, da mesma forma que seus efeitos afetam a prática docente e até mesmo a saúde do professor.

$\mathrm{Na}$ análise dos trabalhos selecionados se identificou que o comportamento dos alunos na escola são cópias daquilo que vivenciam e observam em seu meio social, ou seja, o contexto extraescolar é considerado como um dos desencadeadores da violência que ocorre na escola. Vale ressaltar que os trabalhos analisados retratam a questão da violência em Escolas públicas, mas essa não está restrita somente a estas instituições, ela se faz presente nas Escolas das redes privadas de ensino, em que professores sofrem com violência verbal, moral etc.

A violência nas escolas prejudica o aprendizado, bem como gera consequências para o trabalho do professor. Muitos professores têm dificuldade em lidar com tal situação e se veem impossibilitados de conduzir suas aulas de maneira satisfatória, o que provoca quadro de depressão e o desgaste emocional, que estão associados à síndrome de Burnout. Tais situações geram um sentimento de desvalorização profissional, que podem se refletir em afastamentos do trabalho e até abandono da carreira docente.

Diante deste cenário, é de extrema importância ressaltar que as causas da violência no espaço escolar são amplas e complexas e tem origem nas esferas; social, econômica, cultural, política, além do que a desigualdade social e o pouco investimento do Estado na Educação, em programas sociais, na infra-estrutura urbana e nas condições socioeconômicas, esses também são fatores que acentuam o fenômeno da violência. Na busca de soluções para essa situação a nível de instituição de ensino, é de suma importância a parceria e comprometimento entre família e escola de forma que os pais tenham participação ativa na vida escolar dos seus filhos. As famílias necessitam estar atentas ao comportamento dos alunos dentro e fora da escola. Já as instituições de ensino também têm como encargo promover palestras sobre diversos temas ligados à infância e à juventude, bem como desenvolver projetos pedagógicos com o intuito de esclarecer os direitos e os deveres dos professores e dos estudantes, além de sempre comunicar a família da 


\section{Dialogia}

MEINHART, Daiane Beatriz; SANTOS, Eliane Gonçalves dos. Violência escolar o desafio da atualidade: implicações na prática profissional do professor

conduta dos filhos. Também é importante investir na formação continuada dos professores, para que os mesmos tenham subsídios para atuar num contexto social marcado por expressões de violência.

\section{Referências}

BARDIN, L. Análise de conteúdo. São Paulo: Edições 70, 2011.

CABRAL, F. M. S.; CARVALHO, M. A. V.; RAMOS, R. M. Dificuldades no relacionamento professor/aluno: um desafio a superar. Paidéia, p. 327-335, 2004. Disponível em: $<$ http://www.scielo.br/pdf/paideia/v14n29/08.pdf>. Acesso em: 15 ago. 2018.

CANTE, V. B. Sou professora e fui agredida: a formação do professor para enfrentar a violência da escola. 2014. 151 f. Dissertação (Mestrado em Educação) - Universidade Federal de Mato Grosso, Instituto de Ciências Humanas e Sociais, Rondonópolis, 2014.

FONSECA, K. R. A violência na escola. Rio de Janeiro, 2011. Disponível em: <http://www.avm.edu.br/docpdf/monografias_publicadas/C206286.pdf>. Acesso em: 11 out. 2018.

LEVY, G. C. T. M.; NUNES SOBRINHO, F. P.; SOUZA, C. A. A. Síndrome de Burnout em professores da rede pública. Produção, v. 19, n. 3, p.458-465, set./dez. 2009. Disponível em: <http://www.scielo.br/pdf/prod/v19n3/04.pdf>. Acesso em: 16 nov. 2018.

LÜDKE, M.; ANDRÉ, M. E. D. A. Pesquisa em educação: abordagens qualitativas. São Paulo: EPU, 1986.

MARTINS, A. C. C.; TORRES, M. C. B. S. Violência escolar: uma reflexão sobre suas causas e o papel do Estado. Revista Jus Navigandi, Teresina, ano 21, n. 4925, 2016. Disponível em: < https://jus.com.br/artigos/54350/violencia-escolar-uma-reflexao-sobre-suas-causas-e-o-papeldo-estado >. Acesso em: 10 out. 2018.

MATOS, F. A. S.; VIANA, S. S. A.; GURGEL, C. R. A violência contra professores: saberes e práticas. Campina Grande, 2012. Disponível em: <

http://editorarealize.com.br/revistas/fiped/trabalhos/766ebcd59621e305170616ba3d3dac32.pdf >. Acesso em: 5 jul. 2018.

MOTA, K. J.; SANTOS, L. M. S. Violência nas escolas: propostas pedagógicas por uma cultura de paz. 2011. Disponível em: < https://portal.fslf.edu.br/wp-

content/uploads/2016/12/tcc18.pdf>. Acesso em: 27 mar. 2018.

OLIVEIRA, É.C.S.; MARTINS, S.T.F. Violência, sociedade e escola: da recusa do diálogo à falência da palavra. Psicologia \& Sociedade; 19 (1): 90-98; jan/abr. 2007.

OLIVEIRA, B. C.; SOUZA, H. J. S. A violência nas escolas e as suas causas. Cadernos de Educação: Ensino e Sociedade, Bebedouro-SP, v. 1, n. 1, p. 1-17, 2014. Disponível em:<http://www.unifafibe.com.br/revistasonline/arquivos/cadernodeeducacao/sumario/31/04 042014073727.pdf>. Acesso em: 27 mar. 2018. 
ROUTTI, C. Violência em meio escolar: fatos e representações na produção da realidade. Educaşão e Pesquisa. São Paulo, SP: USP. v. 36, n. 1, p. 339-335, jan/abr. 2010.

SILVA, M. A. I.; PEREIRA, B. O. A violência como fator de vulnerabilidade na ótica de adolescentes escolares. In: BONITO, J. (org). Educação para a Saúde no Século XXI: Teorias, Modelos e Práticas, 2008. p. 912-918

SOARES, M. B. Representações sociais de violência contra professores na escola. 2013. 180 f. Dissertação (Mestrado em Educação) - Universidade Federal de Pernambuco, Recife, 2013.

SODRÉ, C. M. O.; MOURA, M. L.; ALEXANDRE, I. J. Violência no espaço escolar. Revista Eventos Pedagógicos, Mato Grosso, v.3, n.2, p. 315 - 327, Mai/Jul. 2012.

SOUZA, J. C. C.; SANTOS, J. C. A Violência Escolar Contra o Professor no Ensino Fundamental na Escola Municipal Beija Flor segundo Depoimento dos Professores/Guarantã Do Norte-MT. 2013. Disponível em: < revistanativa.com/index.php/revistanativa/article/download/115/pdf > . Acesso em: 18 set. 2018.

TENENTE, L.; FAJARDO, V. Brasil é \#1 no ranking da violência contra professores: entenda os dados e o que se sabe sobre o tema. 2017. Disponível em:

$<$ https://g1.globo.com/educacao/noticia/brasil-e-1-no-ranking-da-violencia-contra-professoresentenda-os-dados-e-o-que-se-sabe-sobre-o-tema.ghtml>. Acesso em: 18 nov. 2018.

Recebido em: 14 abr. 2019 / Aprovado em: 27 fev. 2020

Cite como (ABNT NBR 6023:2018)

MEINHART, Daiane Beatriz; SANTOS, Eliane Gonçalves dos. Violência escolar o desafio da atualidade: implicações na prática profissional do professor. Dialogia, São Paulo, n. 34, p. 244-259, jan./abr. 2020. Disponível em: https://doi.org/10.5585/Dialogia.N34.13611. 